\title{
N-Acetylcysteine Downregulation of Lysyl Oxidase Activity Alleviating Bleomycin-Induced Pulmonary Fibrosis in Rats
}

\author{
Shifeng $\mathrm{Li}^{\mathrm{a}}$ Xiaoxiao Yang ${ }^{\mathrm{a}}$ Wande $\mathrm{Li}^{\mathrm{b}}$ Jingjie $\mathrm{Li}^{\mathrm{a}}$ Xingwen Su${ }^{\mathrm{a}}$ Lijun Chen ${ }^{\mathrm{a}}$ \\ Guangmei Yan ${ }^{a}$ \\ a Department of Pharmacology, Zhongshan School of Medicine, Sun Yat-sen University, Guangzhou, \\ People's Republic of China; ${ }^{b}$ Department of Biochemistry, Boston University School of Medicine, \\ Boston, Mass., USA
}

\section{Key Words}

Fibrosis • Glutathione • Idiopathic pulmonary fibrosis •

$\mathrm{N}$-acetylcysteine $\cdot$ Lysyl oxidase $\cdot$ Pulmonary fibrosis $\cdot$

$\alpha$-Smooth muscle actin • Transforming growth factor- $\beta_{1}$

\begin{abstract}
Background: Idiopathic pulmonary fibrosis (IPF) is a progressive and fatal lung disease without beneficial therapy, except for lung transplantation. A high oral dose of $\mathrm{N}$-acetylcysteine (NAC) added to prednisone and azathioprine has been found to improve lung function in IPF patients, though the mechanism of action remains poorly understood. Objective: Based on our previous findings showing elevation of glutathione (GSH) content associated with downregulation of lysyl oxidase (LOX) activity, which is essential for collagen deposition, the aim of the present study was to test the hypothesis that NAC alleviates IPF by regulating LOX function. Methods: We firstly analyzed the time course of collagen deposition in lung tissue, hydroxyproline content, LOX activity, GSH levels, and transforming growth factor- $\beta_{1}\left(\right.$ TGF- $\left.\beta_{1}\right)$ and $\alpha$-smooth muscle actin ( $\alpha$-SMA) expression in bleomycin (BLM)-induced pulmonary fibrosis in a rat model. Then, we focused our studies on NAC modulation of LOX activity. $\boldsymbol{R e}$ sults: LOX activity was increased on day 9 and peaked 14 days after BLM administration, while TGF- $\beta_{1}$ protein peaked
\end{abstract}

on day 9. Interestingly, NAC treatment for 14 days from day 0 reversed LOX activity to normal levels and increased GSH levels in the lung of BLM-dosed rats. Consistently, NAC partially attenuated pulmonary fibrosis and inhibited TGF- $\beta_{1}$ and $\alpha$-SMA expression in this model. Conclusions: Our study supports a novel mechanism of NAC alleviating IPF by inhibition of LOX activity via elevation of lung GSH in BLM-induced pulmonary fibrosis. The TGF- $\beta_{1} / \alpha$-SMA pathway may also play an important role in modulation of LOX activity.

Copyright $\odot 2012$ S. Karger AG, Basel

\section{Introduction}

Idiopathic pulmonary fibrosis (IPF) is a progressive and lethal lung interstitial disorder, which is characterized by the loss of alveolar structures and functions following apoptosis of epithelial and endothelial cells, proliferation of fibroblasts and excessive deposition of extracellular matrix [1]. Unfortunately, the etiology and mechanisms for IPF pathogenesis remain unclear. Though clinical trials of some agents have suggested a possible benefit, such as pirfenidone [2, 3], interferon, colchicines, bosentan, penicillamine, losartan [4], doxycycline [5] and nilotinib [6] etc., evidence suggests that there is no proven pharmacological therapy for IPF to date $[7,8]$.

\section{KARGER}

Fax +4161306 1234

E-Mail karger@karger.ch

www.karger.com (c) 2012 S. Karger AG, Basel

0025-7931/12/0846-0509\$38.00/0

Accessible online at:

www.karger.com/res
Assoc. Prof. Lijun Chen, MD, $\mathrm{PhD}$

Department of Pharmacology

Zhongshan School of Medicine, Sun Yat-sen University

Guangzhou 510080 (People's Republic of China)

Tel. +862087330138 838, E-Mail chenlij@ mail.sysu.edu.cn 
An oxidant-antioxidant imbalance may play a critic role in the pathogenesis of IPF. The level of glutathione (GSH), a major antioxidant, was decreased to approximately one third of the normal concentration in IPF [9]. $\mathrm{N}$-acetyl-L-cysteine (NAC), a precursor of GSH acting as a free radical scavenger, has been shown to restore pulmonary GSH levels in patients with IPF [10] and attenuate early inflammatory responses and late fibrotic lesions in bleomycin (BLM)-dosed animals [11-14]. In a double-blind, randomized, placebo-controlled multicenter clinical trial (the IFIGENIA trial), high-dose, oral NAC in combination with prednisone and azathioprine markedly improved lung function in IPF patients $[15,16]$. A recruiting clinical trial (the PANTHER-IPF study, NCT00650091) showed that the three-drug regimen of prednisone + azathioprine + NAC led to a significant increase in mortality and serious adverse events, and therefore this arm was stopped, but the two remaining arms of the study, NAC alone against placebo, are still under investigation with results expected in the third quarter of 2013. Still, NAC may be a promising treatment of IPF and its mechanisms of action upon the lung remain unresolved.

Lysyl oxidase (LOX), a copper-dependent enzyme, oxidizes specific lysine residues in collagen and elastin leading to the formation of inter- or intramolecular crosslinks essential for stabilization of the extracellular matrix [17]. Strong evidence supports an association of pulmonary fibrosis with elevated LOX activity $[18,19]$. In a study by Counts et al. [20], elevation of LOX activity preceded the maximal increase in total lung hydroxyproline (HYP) elicited by BLM in rats. LOX was upregulated in cultured human fetal lung fibroblasts exposed to BLM [21]. $\beta$-Aminopropionitrile [22], an LOX inhibitor, as well as taurine and niacin [23] prevented BLM-induced pulmonary fibrosis in hamsters. Thus, LOX may be a critical target of antifibrosis [24].

Our previous studies indicated that enhancement of cellular GSH by GSH monoethyl ester decreased levels of LOX protein species and catalytic activity in vitro [25]. Elevation of cellular GSH induced reduction of LOX activity in cells exposed to cigarette smoke condensate or cadmium [26]. These findings support the possibility that NAC may ameliorate IPF at least in part via downregulation of LOX. In this study, we examined whether NAC attenuates pulmonary fibrosis by modulation of LOX activity in the BLM animal model in an effort to provide critical information beneficial for IPF treatment.

\section{Materials and Methods}

\section{Reagents}

BLM hydrochloride A2 was purchased from Nippon Kayak, Japan; NAC from Sigma-Aldrich, USA, and polyclonal antibodies to TGF- $\beta_{1}$ (sc-146) and $\alpha$-smooth muscle actin ( $\alpha$-SMA; ab5694) from Santa Cruz Biotechnology, USA, and Abcam, USA, respectively.

\section{Animal Model and Experimental Protocol}

All experiments were performed according to international and institutional guidelines for animal care and were approved by the Sun Yat-sen University Animal Care and Use Committee. All surgery procedures were performed under sodium pentobarbital anesthesia, and all efforts were made to minimize suffering.

Pathogen-free, male Sprague-Dawley rats weighing 200-250 g were from the Experimental Animal Center of the Southern Medical University (Guangzhou, China) and kept with water and standard rodent chow ad libitum. To start experiments, BLM was dissolved in sterile saline to the final concentration of $5 \mathrm{mg} / \mathrm{ml}$. Animals received a single intratracheal instillation of BLM at a dose of $5 \mathrm{mg} / \mathrm{kg}$ body weight on day 0 . Control animals were instilled with the same volume of saline only.

To investigate the time course of pulmonary LOX activity in the rat BLM model, treated animals were sacrificed on days 9, 14, 28 and 35 in experiment 1 . Since we focused on the late fibrotic phase of the model, based on the literature published [27], day 9 was selected as the starting time point and day 14 was a time point at which lung fibrotic lesions and LOX activities were tested after BLM administration. Animals in the control group were sacrificed on day 14 ( $n=5$ /group).

Secondly, to investigate the effect of NAC on LOX activity in this model, animals were randomly divided into three groups ( $\mathrm{n}=5$ /group) in experiment 2 , i.e. the control group (saline + deionized water), the $\mathrm{B}+\mathrm{W}$ group (BLM + deionized water) and the $\mathrm{B}+\mathrm{N}$ group $(\mathrm{BLM}+\mathrm{NAC})$. Treatments (deionized water or NAC) were administered orally by gavage on a daily basis (at 9:00 am) from day 0 . All animals were sacrificed on day 14 . The oral dose of NAC was $490 \mathrm{mg} / \mathrm{kg}$ per day. NAC was dissolved in deionized water to the final concentration of $122.5 \mathrm{mg} / \mathrm{ml}$ for the animals, as described [14, 28].

Left lungs in all animals were used for histological assessment. Right lungs were removed en bloc after clearing the major visible bronchi, blotted dry, weighed, homogenated in 2 volumes of Tris$\mathrm{HCl}$ buffer $(50 \mathrm{mM}, \mathrm{pH} 7.4)$, stored at $-80^{\circ} \mathrm{C}$ for biochemical assays, such as HYP content, protein expression of transforming growth factor- $\beta_{1}$ (TGF- $\left.\beta_{1}\right)$, a profibrotic factor, and $\alpha$-SMA, a marker of myofibroblast differentiation, GSH concentration and LOX activity.

Histology

For histological studies, the left lungs were perfused via the main bronchus with $10 \%$ neutral-buffered formalin and fixed in this fixative solution for $24 \mathrm{~h}$. Tissue blocks were dehydrated in a graded series of ethanols, embedded in paraffin, cut into $4-\mu \mathrm{m}$ thick serial sections and processed for hematoxylin-eosin (HE) and Masson's trichrome staining.

\section{HYP Content}

Pulmonary collagen deposition was quantitatively assessed by the HYP assay with the HYP detection kit (Nanjng Jiancheng Bio- 
engineering Institute, China) according to the manufacturer's instructions. Briefly, Lung tissue samples were homogenized and hydrolyzed at $100^{\circ} \mathrm{C}$ for $20 \mathrm{~min}$, adjusted to a suitable $\mathrm{pH}$ value and added to active carbon. After centrifugation, $500 \mu \mathrm{l}$ of the supernatant were mixed with the HYP chromogenic agent and measured as absorbance at $540 \mathrm{~nm}\left(\mathrm{~A}_{540}\right)$ using an iMark microplate reader (Bio-Rad, USA) [29] and the HYP concentration was determined (expressed as $\mu \mathrm{g} / \mathrm{g}$ wet lung).

\section{Western Immunoblotting}

Homogenized lung samples were lysed in 6 volumes of ice-cold M-PER@mammalian protein extraction reagent with cocktail proteinase inhibitors and $4 \mathrm{~mol} / \mathrm{l}$ urea (Pierce Biotechnology, USA). Protein concentration was assessed using the Pierce BCA protein assay kit (Pierce Biotechnology). Equal amounts of protein were separated by 12 (for $\alpha$-SMA) or $15 \%$ (for TGF- $\beta_{1}$ ) SDSPAGE. After electrophoresis, the proteins were transferred to PVDF membrane, blocked with 5\% skimmed milk in TBS for $1 \mathrm{~h}$ at room temperature and reacted with antibodies against TGF- $\beta_{1}$ (1:500) or $\alpha$-SMA $(1: 200)$ at $4^{\circ} \mathrm{C}$ overnight. After reaction with horseradish peroxidase-labeled secondary antibody, the immune complexes were visualized using the ECL detection reagents following the manufacturer's instructions.

\section{LOX Activity Assessment}

Total LOX activity in rat lung tissue was assayed with the methods reported by Palamakumbura [30]. In brief, lung homogenization samples were mixed with 3.5 volumes of extraction buffer containing $1.2 \mathrm{~mol} / \mathrm{l}$ urea and $50 \mathrm{mmol} / \mathrm{l}$ sodium borate $(\mathrm{pH}$ 8.2) reacted at $4^{\circ} \mathrm{C}$ overnight. After centrifugation, supernatant was added to the reaction mixture containing $50 \mathrm{mmol} / \mathrm{l}$ sodium borate, $1.2 \mathrm{~mol} / \mathrm{l}$ urea, $\mathrm{pH} 8.2,1 \mathrm{unit} / \mathrm{ml}$ horseradish peroxidase (Roche, Switzerland), $10 \mu \mathrm{mol} / \mathrm{l}$ Amplex red (Invitrogen, USA) and $10 \mathrm{mmol} / \mathrm{l} 1.5$-diaminopentane (Sigma) with or without 0.5 $\mathrm{mmol} / \mathrm{l} \beta$-aminopropionitrile (Sigma), an inhibitor of LOX. Samples were incubated at $37^{\circ} \mathrm{C}$ for $30 \mathrm{~min}$ and placed on ice. The difference in fluorescence intensity was recorded at excitation and emission wavelengths of 563 and $587 \mathrm{~nm}$, respectively, using a Hitachi 850 fluorescence spectrophotometer (Hitachi Instruments, Japan). All enzyme activities were expressed as fluorescence at $587 \mathrm{~nm}$, corrected for background levels of fluorescence determined in the reaction mixture supplemented with $\beta$-aminopropionitrile. Assays were repeated three times for all samples.

\section{Total Lung GSH Content Assay}

Total lung GSH content in rats was determined by the enzymatic recycling method, as described previously [31]. Briefly, lung homogenization samples were added to 3.5 volumes of ice-cold extraction solution containing $0.1 \%$ Triton X-100 and $0.6 \%$ sulfosalicylic acid in KPE $(0.1 \mathrm{mmol} / \mathrm{l} \mathrm{PBS}$ with $5 \mathrm{mmol} / \mathrm{l}$ EDTA disodium salt, $\mathrm{pH} 7.5$ ) reacted at $4^{\circ} \mathrm{C}$ for $30 \mathrm{~min}$. After centrifugation, $20 \mu \mathrm{l}$ supernatant were transferred to a 96 -well microtiter plate, and $120 \mu \mathrm{l}$ reaction mixture containing $0.33 \mathrm{mg} / \mathrm{ml} \mathrm{NTNB}$ (Roche) and 1.67 units/ml GSH reductase (Sigma) were added, incubated for $30 \mathrm{~s}$, then $60 \mu \mathrm{l} \beta$-NADPH (Roche) were added and absorbance was read at $415 \mathrm{~nm}\left(\mathrm{~A}_{415}\right)$ every $30 \mathrm{~s}$ for $2 \mathrm{~min}$. GSH content was described as change in absorbance/min corrected for the background determined using KPE only. Assays were repeated three times for each sample.

NAC Alleviates Pulmonary Fibrosis via LOX in Rats
Statistical Analysis

SigmaPlot v11.1 (Systat Software, USA) was used for statistical analysis. Data are expressed as means \pm SD. Comparisons were made using one-way analysis of variance followed by a least-significant difference post hoc test. $\mathrm{p}<0.05$ was considered statistically significant.

\section{Results}

\section{The Effect of NAC on Lung Histology in the}

\section{Rat BLM Model}

HE-stained lung sections were examined light microscopically. Figure 1a shows normal lung histology (control group). Nine days after BLM administration, alveolar septal thickening was accompanied by marked peribronchiolar and interstitial infiltration with macrophages, lymphocytes, neutrophils and fibroblasts. Such inflammatory cells were also distributed in some alveolar spaces. On day 14, alveolar septal thickening and cellular infiltration became more severe, and fibroblastic foci (the hallmark of IPF) appeared. On days 28 and 35, fibroblastic foci were increased, alveolar architectures collapsed and diffuse fibrosis formed. Notably, at these times bronchi were filled with diapyetic neutrophils. In experiment 2 , after 14 days of oral NAC, although inflammatory and fibrotic lesions were still present in the lungs, less fibroblastic foci, widening alveolar septa and decreased inflammatory cell infiltration were observed in the $\mathrm{B}+\mathrm{N}$ group in comparison to those in the $\mathrm{B}+\mathrm{W}$ group (fig. 1b).

\section{Effect of NAC on Pulmonary Collagen Deposition}

Masson's trichrome staining revealed markedly increased collagen deposition from days 9 to 35 (fig. 1a). The increase in collagen deposition was associated with a loss of alveolar structures. Consistently, HYP content, an index for collagen accumulation, was significantly elevated on day 9 ( $p<0.01$ vs. control) and remained increased up to the end of the experiment (fig. 1c). Clearly, BLM causes a strong lung-fibrotic response characterized by a time-dependent collagen deposition. Consistent with the histological results, NAC intervention also resulted in a tendency to a lower HYP content in the lung of NAC-treated rats exposed to BLM, though the difference failed to reach significance (fig. 1d).

\section{Effect of NAC on LOX Activity}

As shown in figure $2 \mathrm{a}$, LOX activity in BLM-dosed lungs was increased to 2.3-fold of the control on day 9, reached a peak amounting to 4.7-fold of the control on day $14(\mathrm{p}<0.01)$ and subsequently returned to the day 9 


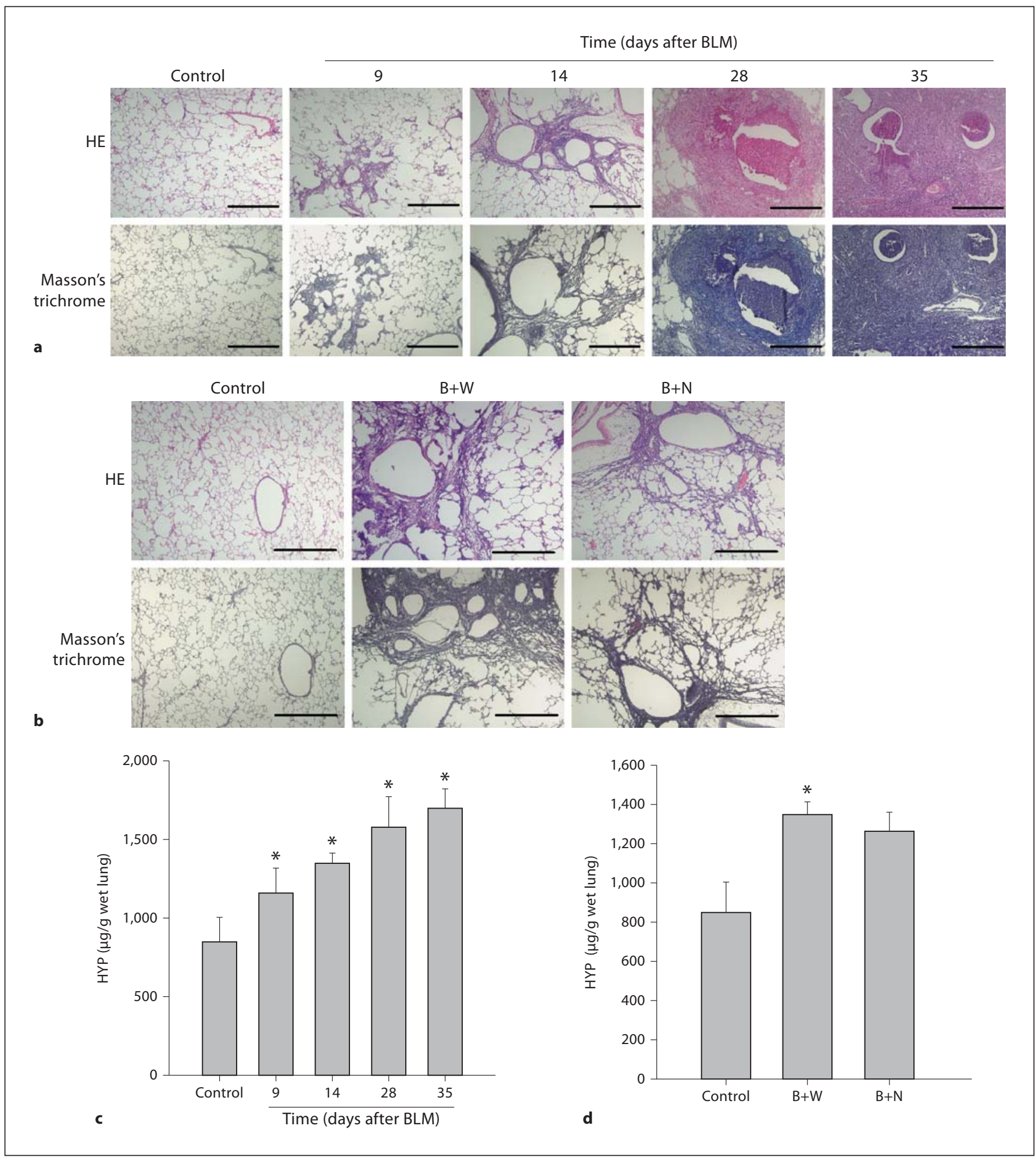

Fig. 1. Histopathologic changes and collagen deposition in lungs from BLM-treated rats with or without NAC intervention. a, b Fibrosis was assessed by HE and Masson's trichrome staining. Each photomicrograph is representative for each group. Scale bars $=500 \mu \mathrm{m}$. c, d Pulmonary collagen deposition was quanti- tatively evaluated by testing HYP content. Each value represents the mean $\pm S D$ in each group $\left(n=5 /\right.$ group). ${ }^{*} \mathrm{p}<0.001 \mathrm{vs.} \mathrm{control}$ group. b, $\mathbf{d}$ All animals were sacrificed 14 days after BLM administration. 


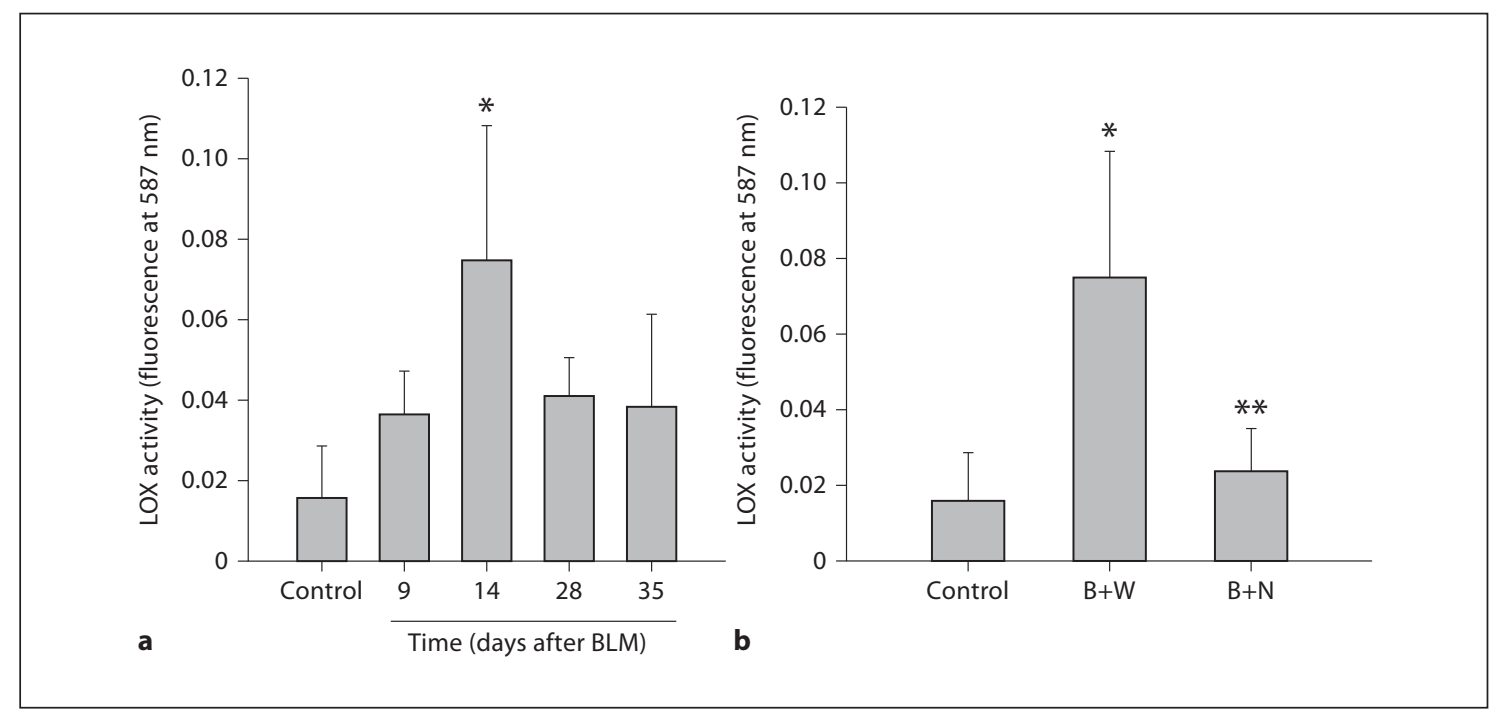

Fig. 2. LOX activity in lungs from BLM-treated rats with or without NAC intervention. a Animals treated with BLM were sacrificed on days 9, 14, 28 and 35. b All animals were sacrificed 14 days after BLM administration. Total lung LOX activity was expressed as the mean $\pm \mathrm{SD}$ of each group ( $\mathrm{n}=5$ /group). ${ }^{*} \mathrm{p}<0.01$ vs. control group, ${ }^{* *} \mathrm{p}<0.05$ vs. $\mathrm{B}+\mathrm{W}$ group.

level 28 and 35 days after BLM administration. Interestingly, NAC treatment $(\mathrm{B}+\mathrm{N})$ almost completely abolished the elevation in LOX activity on day 14 induced by BLM (decrease to $31.7 \%$ of the $\mathrm{B}+\mathrm{W}$ control; $\mathrm{p}<0.05$; fig. $2 \mathrm{~b}$ ).

\section{Effect of NAC on Total Lung GSH Levels}

To test the oxidant stress induced by BLM, GSH concentration in lung tissue was assessed. BLM caused a significant reduction in GSH concentration at all experimental time points in experiment 1 , as previously reported [14] (fig. 3a).

NAC, a precursor of GSH, is able to restore pulmonary GSH levels. In experiment 2, BLM reduced the GSH concentration in lung tissue of the $\mathrm{B}+\mathrm{W}$ group to $29.5 \%$ of the control $(p<0.001)$. NAC treatment reversed this effect; $70.7 \%$ of the control and $239.6 \%$ of the $\mathrm{B}+\mathrm{W}$ group levels of pulmonary GSH were recovered ( $p<0.001$; fig. $3 b$ ).

\section{Effects of NAC on TGF- $\beta_{1}$ and $\alpha$-SMA}

TGF- $\beta_{1}$ activation of myofibroblasts plays a central role in the progression of IPF, and this may be involved in the modulation of LOX by BLM. In the control group, TGF- $\beta_{1}$ expression was weak. The expression of TGF- $\beta_{1}$ increased markedly (62.1-fold of control), peaked on day 9 and remained elevated up to 35 days after BLM administration (fig. 4a). The trend of $\alpha$-SMA, a marker of myofibroblast differentiation, was similar to LOX activity ex- pression, i.e. it was elevated on day 9 (2.4-fold of control) and reached a plateau on day 14 (4.1-fold of control; fig. 4c), indicating that myofibroblasts may be the main cellular source of LOX. Moreover, the peak of TGF- $\beta_{1}$ preceded that of $\alpha$-SMA revealing the role of TGF- $\beta_{1}$ in myofibroblast differentiation, as previously reported [32].

NAC treatment partially inhibited the upregulation of TGF- $\beta_{1}$ (0.7-fold of B+W group) and $\alpha$-SMA (0.6-fold of $\mathrm{B}+\mathrm{W}$ group) protein induced by BLM (fig. $4 \mathrm{~b}, \mathrm{~d}$ ).

\section{Discussion}

IPF has been a real challenge for its unknown etiology and pathogenic mechanism, resulting in dimmed therapy and poor prognosis. Three- and 5-year mortality rates of approximately $50-80 \%$ were reported for patients after diagnosis [33]. There are no data reporting improved survival or quality of life for patients with IPF with the currently available treatments. In patients receiving lung transplantation, 5-year survival approximates 50-56\% [7]. The IFIGENIA trial demonstrated that a high oral dose of NAC, which was added to prednisone and azathioprine, preserves the vital capacity and single-breath carbon monoxide diffusing capacity of patients [15], rendering NAC a promising IPF treatment, but the results of the PANTHER-IPF study will provide more information. 


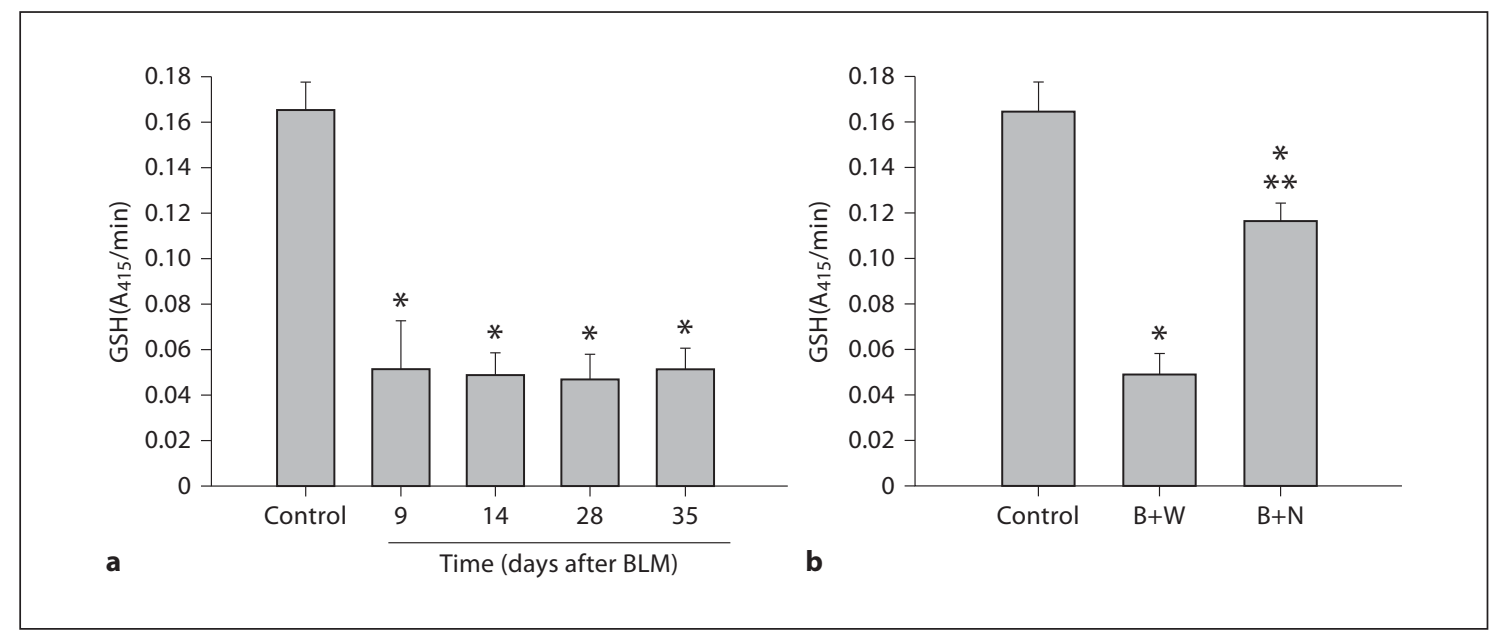

Fig. 3. Total GSH content in lungs from BLM-treated rats with or without NAC intervention. a Animals treated with BLM were sacrificed on days 9, 14, 28 and 35. b All animals were sacrificed 14 days after BLM administration. Each value represents the mean $\pm \mathrm{SD}\left(\mathrm{n}=5\right.$ /group). ${ }^{*} \mathrm{p}<0.001$ vs. control group, ${ }^{* *} \mathrm{p}<0.001 \mathrm{vs}$. $\mathrm{B}+\mathrm{W}$ group.

In animal studies, NAC was found to ameliorate BLMinduced pulmonary fibrosis via the regulation of several key factors, such as attenuation of acute pulmonary inflammation via a decrease in chemokine and lipid hydroperoxide levels, improved pulmonary antioxidant protection, scavenging of reactive oxygen species and detoxification of BLM-generated radicals $[11,13]$. However, the antifibrotic mechanism of NAC is still unknown.

LOX is an amino oxidase which catalyzes the oxidative deamination of specific lysine residues in collagen and elastin, leading to inter- or intramolecular crosslinks. As a result, LOX may play an important role in the pathogenesis of IPF, as it is essential for the insolubilization and stabilization of extracellular matrix proteins [17], i.e. the hallmark of IPF. Actually, a strong association between pulmonary fibrosis and elevated LOX activity was reported [18-20], and inhibition of LOX activity prevented BLM-induced pulmonary fibrosis $[22,23]$. We have found that BLM increased LOX activity in vitro in our previous work [21] and in vivo in this study. Furthermore, we also noted that increasing GSH downregulated LOX catalytic activity in vitro [25]. NAC is able to restore pulmonary GSH levels in IPF [10]. In this study, NAC reversed the content of GSH, inhibited LOX activity induced by BLM and partially alleviated pulmonary fibrosis in a rat model of BLM-induced IPF. Thus, downregulation of LOX activity by NAC may play a critical role in alleviation of BLM-induced pulmonary fibrosis in rats.
GSH, accounting for $90 \%$ of total cellular non-protein thiols [26], is shown to inhibit LOX activity. LOX is a metalloenzyme requiring $\mathrm{Cu}$ (II) as a cofactor for enzymatic function, which is added to the LOX active center through the secretory pathway and essential for the formation and the maintenance of the carbonyl cofactor identified as lysine tyrosylquinone [34]. Thiol-containing GSH and metallothionein are critical modulators for $\mathrm{Cu}$ metabolism. Freedman et al. [35] reported that $\mathrm{Cu}$ forms complexes with GSH soon after cell entry which were then transferred to metallothionein, providing temporary storage for cytoplasmic $\mathrm{Cu}$. In fact, the majority of cytoplasmic $\mathrm{Cu}(>60 \%)$ is isolated as GSH complexes [35]. Downregulation of LOX is observed in cultured RFL6 cells exposed to cigarette smoke condensate or cadmium when cells were treated with GSH monoethyl ester, a GSH delivery system [20]. NAC, a cell-permeable sulfhydryl compound, readily enters cells and promotes the production of GSH by furnishing its limiting precursor, L-cysteine [36]. In this study, we demonstrated that oral NAC restores pulmonary GSH levels in BLM-treated rats, which is accompanied by inhibition of LOX activity. In contrast, depletion of pulmonary GSH and upregulation of LOX activity occurs in rats exposed to BLM without NAC treatment. Clearly, a possible mechanism is NACinduced elevation of GSH in the lung tissue of rats may largely trap cellular $\mathrm{Cu}$, thus limiting its biological availability for LOX leading to downregulation of LOX activity. 
Fig. 4. TGF- $\beta_{1}$ and $\alpha$-SMA protein expression in lungs from BLM-treated rats with or without NAC intervention. TGF- $\beta_{1}(\mathbf{a}$, b) and $\alpha$-SMA (c, d) were assessed by Western blot. b, d All animals were sacrificed 14 days after BLM administration. Experiments were repeated thrice. Data shown are the mean $\pm \mathrm{SD}(\mathrm{n}=3)$ of TGF- $\beta_{1} / \alpha$-SMA normalized to $\beta$-actin/ tubulin band densities. ${ }^{*} \mathrm{p}<0.001$ vs. control, ${ }^{* *} \mathrm{p}<0.001$ vs. $\mathrm{B}+\mathrm{W}$ group.

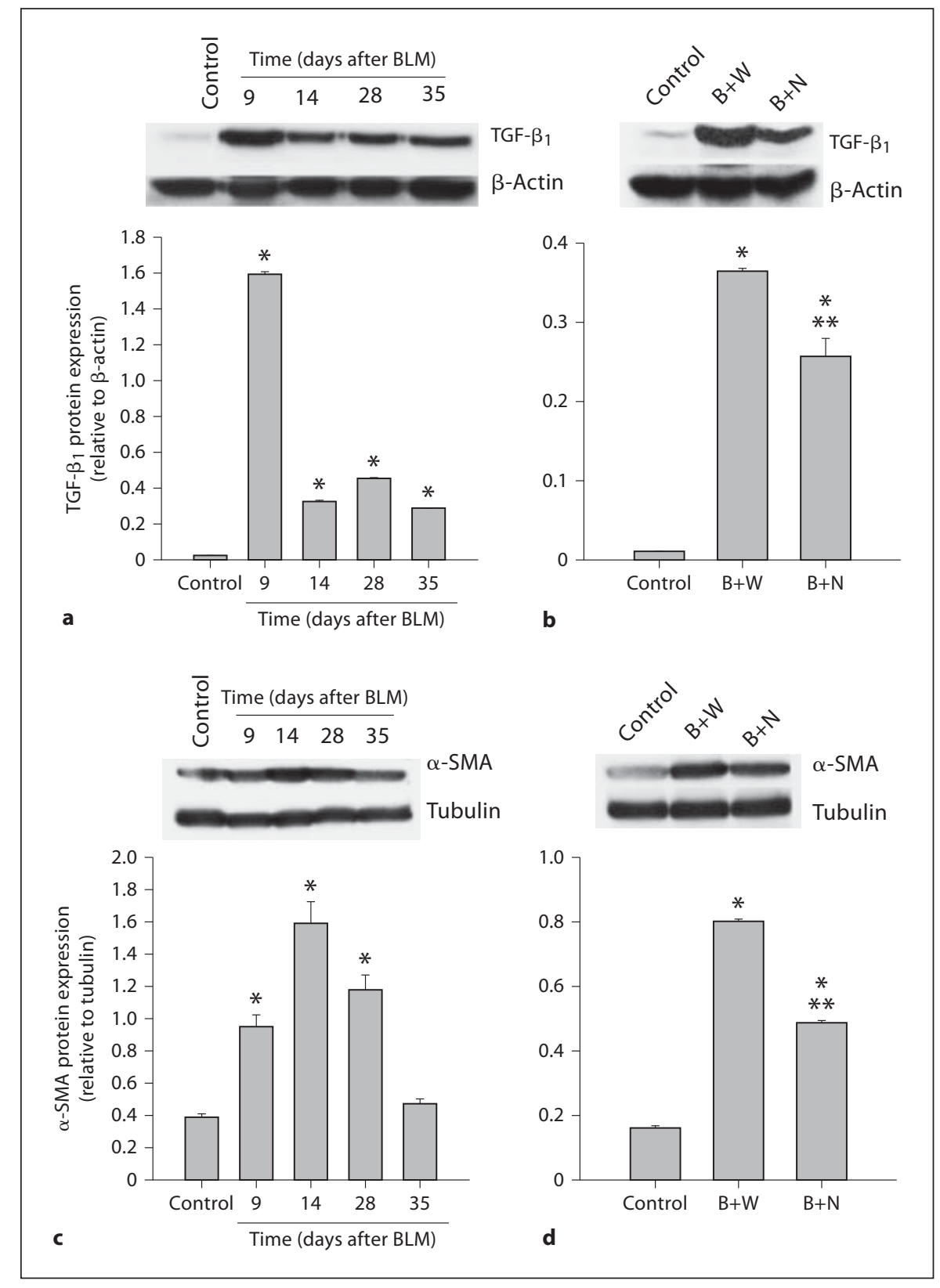

LOX is expressed in a variety of cell types, such as fibroblasts, aortic and lung smooth muscle cells, myofibroblasts and corneal endothelial cells [37, 38]. However, the source(s) of LOX in lung tissues, especially during IPF development, is little known. TGF- $\beta_{1}$, a fibrogenic growth factor regulating collagen synthesis and deposition, fibroblast proliferation and transformation to myofibroblasts, has been found to strongly promote expression of LOX in vitro, e.g. in fibroblasts from neonatal rat lungs [39], and in rat vascular smooth muscle cells [40]. This study showed that BLM caused strong expression of TGF$\beta_{1}$ on day 9 , and the elevated level of TGF- $\beta_{1}$ was maintained up to day 35. Additionally, the myofibrobast differentiation marker $\alpha$-SMA started to increase from day 9 and peaked on day 14 , followed by a gradual decrease to very low levels. These two findings indicate that the BLMinduced increase in the number of lung myofibroblasts might mainly be mediated by the TGF- $\beta_{1}$ pathway, in agreement with previous reports [32, 41]. Since there was a significant correlation between $\alpha$-SMA and LOX ex- 
pression, we speculate that myofibroblasts may be the main source of LOX in BLM-induced pulmonary fibrosis. Thus, TGF- $\beta_{1}$ and myofibroblasts play a central role in BLM-induced upregulation of LOX. Since oral administration of NAC for 14 days partially inhibited TGF- $\beta_{1}$ and $\alpha$-SMA protein levels, NAC may attenuate pulmonary fibrosis and regulate LOX activity via downregulation of the TGF- $\beta_{1} / \alpha$-SMA pathway in this model.

The potential of NAC to attenuate lung injury and subsequent fibrosis is partially dependent on the dose of $\mathrm{BLM}$, the timing and the route of NAC used, the animal species and the strain [14]. In the literature, high doses of oral, aerosolized, intraperitoneal NAC significantly reduced collagen deposition only when NAC was given 1-7 days prior to BLM exposure in rats and mice $[11,13,14$, 28]. Cortijo et al. [14] reported that $490 \mathrm{mg} / \mathrm{kg}$ NAC given orally 1 or 7 days before BLM significantly decreased HYP values in rat lungs, but NAC treatment at the same dose starting 7 days after BLM treatment failed to reduce HYP levels [14]. In our study, NAC was given concomitantly with BLM at the same dose and via the same route as in the study by Cortijo et al. [14]. However, results show that this procedure is limited regarding the attenuation of the HYP content in lungs of rats exposed to BLM. Thus, timing of NAC treatment is critical for its antifibrotic effect. Therefore, as the American Thoracic Soci- ety suggests, therapy should be started at the first identification of clinical or physiological evidence of impairments or documentation of lung function decline in selected cases [7].

\section{Conclusions}

Oral high-dose NAC inhibits LOX activity via a decrease in pulmonary GSH levels, which trap the cofactor of LOX, cellular $\mathrm{Cu}$. Furthermore, BLM increases LOX activity possibly via the TGF- $\beta_{1} / \alpha$-SMA pathway, and myofibroblasts may be one of the main sources of LOX in this animal model. Additional studies are required to further elucidate the precise mechanism(s). NAC is a promising therapy of IPF and largely free of adverse effects. The regulatory potential of NAC on LOX may be a critical basis for its beneficial effect on IPF.

\section{Acknowledgments}

We would like to thank Guangming Yuan, Dadi Chen, Jianping Yu, Guangyun Lin and Yang Li for excellent technical assistance. This work was supported by a research grant from the National Natural Science Foundation of China (No. 30772606).

\section{References}

1 American Thoracic Society/European Respiratory Society International Multidisciplinary Consensus Classification of the Idiopathic Interstitial Pneumonias. This joint statement of the American Thoracic Society (ATS), and the European Respiratory Society (ERS) was adopted by the ATS board of directors, June 2001 and by the ERS Executive Committee, June 2001. Am J Respir Crit Care Med 2002;165:277-304.

-2 Noble PW, Albera C, Bradford WZ, Costabel U, Glassberg MK, Kardatzke D, King TE Jr, Lancaster L, Sahn SA, Szwarcberg J, et al: Pirfenidone in patients with idiopathic pulmonary fibrosis (CAPACITY): two randomised trials. Lancet 2011;377:1760-1769.

-3 Taniguchi H, Ebina M, Kondoh Y, Ogura T, Azuma A, Suga M, Taguchi Y, Takahashi H, Nakata K, Sato A, et al: Pirfenidone in idiopathic pulmonary fibrosis. Eur Respir J 2010; 35:821-829.

-4 Yao HW, Zhu JP, Zhao MH, Lu Y: Losartan attenuates bleomycin-induced pulmonary fibrosis in rats. Respiration 2006; 73:236242.
5 Fujita H, Sakamoto N, Ishimatsu Y, Kakugawa T, Hara S, Hara A, Amenomori M, Ishimoto H, Nagata T, Mukae H, et al: Effects of doxycycline on production of growth factors and matrix metalloproteinases in pulmonary fibrosis. Respiration 2011;81:420-430.

-6 Rhee CK, Lee SH, Yoon HK, Kim SC, Lee SY, Kwon SS, Kim YK, Kim KH, Kim TJ, Kim JW: Effect of nilotinib on bleomycin-induced acute lung injury and pulmonary fibrosis in mice. Respiration 2011;82:273-287.

7 Raghu G, Collard HR, Egan JJ, Martinez FJ, Behr J, Brown KK, Colby TV, Cordier J, Flaherty KR, Lasky JA, et al: An offical ATS/ ERS/JRS/ALAT statement: idiopathic pulmonary fibrosis: evidence-based guidelines for diagnosis and management. Am J Respir Crit Care Med 2011;183:788-824.

8 Khalil N, O'Connor R: Idiopathic pulmonary fibrosis: current understanding of the pathogenesis and the status of treatment. CMAJ 2004;171:153-160.
9 Cantin AM, Hubbard RC, Crystal RG: Glutathione deficiency in the epithelial lining fluid of the lower respiratory tract in idiopathic pulmonary fibrosis. Am Rev Respir Dis 1989;139:370-372.

10 Meyer A, Buhl R, Magnussen H: The effect of oral $\mathrm{N}$-acetylcysteine on lung glutathione levels in idiopathic pulmonary fibrosis. Eur Respir J 1994;7:431-436.

-11 Shahzeidi S, Sarnstrand B, Jeffery PK, McAnulty RJ, Laurent GJ: Oral N-acetylcysteine reduces bleomycin-induced collagen deposition in the lungs of mice. Eur Respir J 1991;4:845-852.

12 Serrano-Mollar A, Closa D, Prats N, Blesa S, Martinez-Losa M, Cortijo J, Estrela JM, Morcillo EJ, Bulbena O: In vivo antioxidant treatment protects against bleomycin-induced lung damage in rats. Br J Pharmacol 2003;138:1037-1048.

13 Hagiwara SI, Ishii Y, Kitamura S: Aerosolized administration of $\mathrm{N}$-acetylcysteine attenuates lung fibrosis induced by bleomycin in mice. Am J Respir Crit Care Med 2000; 162:225-231. 


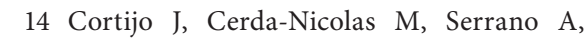
Bioque G, Estrela JM, Santangelo F, Esteras A, Llombart-Bosch A, Morcillo EJ: Attenuation by oral $\mathrm{N}$-acetylcysteine of bleomycininduced lung injury in rats. Eur Respir J 2001; 17:1228-1235.

- 15 Demedts M, Behr J, Buhl R, Costabel U, Dekhuijzen R, Jansen HM, MacNee W, Thomeer M, Wallaert B, Laurent F, et al: Highdose acetylcysteine in idiopathic pulmonary fibrosis. N Engl J Med 2005;353:2229-2242.

- 16 Behr J, Demedts M, Buhl R, Costabel U, Dekhuijzen RPN, Jansen HM, MacNee W, Thomeer M, Wallaert B, Laurent F, et al: Lung function in idiopathic pulmonary fibrosis - extended analyses of the IFIGENIA trial. Respir Res 2009;10:101.

17 Grimsby JL, Lucero HA, Trackman PC, Ravid K, Kagan HM: Role of lysyl oxidase propeptide in secretion and enzyme activity. J Cell Biochem 2010;111:1231-1243.

-18 Kagan HM, Li W: Lysyl oxidase: properties, specificity, and biological roles inside and outside of the cell. J Cell Biochem 2003;88: 660-672.

19 Almassian B, Trackman PC, Iguchi H, Boak A, Calvaresi D, Kagan HM: Induction of lung lysyl oxidase activity and lysyl oxidase protein by exposure of rats to cadmium chloride: properties of the induced enzyme. Connect Tissue Res 1991;25:197-208.

-20 Counts DF, Evans JN, Dipetrillo TA, Sterling KM Jr, Kelley J: Collagen lysyl oxidase activity in the lung increases during bleomycininduced lung fibrosis. J Pharmacol Exp Ther 1981;219:675-678.

-21 Chen LJ, Li WD, Li SF, Su XW, Lin GY, Huang YJ, Yan GM: Bleomycin induces upregulation of lysyl oxidase in cultured human fetal lung fibroblasts. Acta Pharmacol Sin 2010;31:554-559.

22 Riley DJ, Kerr JS, Berg RA, Ianni BD, Pietra GG, Edelman NH, Prockop DJ: $\beta$-Aminopropionitrile prevents bleomycin-induced pulmonary fibrosis in the hamster. Am Rev Respir Dis 1982;125:67-73.
23 Blaisdell RJ, Giri SN: Mechanism of antifibrotic effect of taurine and niacin in the multidose bleomycin-hamster model of lung fibrosis: inhibition of lysyl oxidase and collagenase. J Biochem Toxicol 1995;10:203-210.

24 Kagan HM: Intra- and extracellular enzymes of collagen biosynthesis as biological and chemical targets in the control of fibrosis. Acta Trop 2000;77:147-152.

25 Chen LJ, Zhao Y, Gao S, Chou IN, Toselli P, Stone P, Li W: Downregulation of lysyl oxidase and upregulation of cellular thiols in rat fetal lung fibroblasts treated with cigarette smoke condensate. Toxicol Sci 2005;83:372379.

26 Li W, Zhou J, Chen L, Luo Z, Zhao Y: Lysyl oxidase, a critical intra- and extra-cellular target in the lung for cigarette smoke pathogenesis. Int J Environ Res Public Health 2011; 8:161-184.

27 Chaudhary NI, Schnapp A, Park JE: Pharmacologic differentiation of inflammation and fibrosis in the rat bleomycin model. Am J Respir Crit Care Med 2006;173:769-776.

28 Yildirim Z, Kotuk M, Iraz M, Kuku I, Ulu R, Armutcu F, Ozen S: Attenuation of bleomycin-induced lung fibrosis by oral sulfhydryl containing antioxidants in rats: erdosteine and $\mathrm{N}$-acetylcysteine. Pulm Pharmacol Ther 2005; 18:367-373.

29 Xiao H, Lei H, Qin S, Ma K, Wang X: TGF- $\beta 1$ expression and atrial myocardium fibrosis increase in atrial fibrillation secondary to rheumatic heart disease. Clin Cardiol 2010; 33:149-156.

30 Palamakumbura A: A fluorometric assay for detection of lysyl oxidase enzyme activity in biological samples. Anal Biochem 2002;300: 245-251.

-31 Rahman I, Kode A, Biswas SK: Assay for quantitative determination of glutathione and glutathione disulfide levels using enzymatic recycling method. Nat Protoc 2007;1: 3159-3165.
2 Tomasek JJ, Gabbiani G, Hinz B, Chaponnier C, Brown RA: Myofibroblasts and mechano-regulation of connective tissue remodelling. Nat Rev Mol Cell Biol 2002;3: 349-363.

33 Spruit MA, Janssen DJ, Franssen FM, Wouters EF: Rehabilitation and palliative care in lung fibrosis. Respirology 2009;14:781-787.

-34 Kosonen T, Uriu-Hare JY, Clegg MS, Keen CL, Rucker RB: Incorporation of copper into lysyl oxidase. Biochem J 1997;327(Pt 1):283289.

35 Freedman JH, Ciriolo MR, Peisach J: The role of glutathione in copper metabolism and toxicity. J Biol Chem 1989;264:5598-5605.

36 Cotgreave IA: N-acetylcysteine: pharmacological considerations and experimental and clinical applications. Adv Pharmacol 1997; 38:205-227.

- 37 Peyrol S, Raccurt M, Gerard F, Gleyzal C, Grimaud JA, Sommer P: Lysyl oxidase gene expression in the stromal reaction to in situ and invasive ductal breast carcinoma. Am J Pathol 1997;150:497-507.

38 Fujimaki T, Hotta Y, Sakuma H, Fujiki K, Kanai A: Large-scale sequencing of the rabbit corneal endothelial cDNA library. Cornea 1999;18:109-114.

39 Boak AM, Roy R, Berk J, Taylor L, Polgar P, Goldstein RH, Kagan HM: Regulation of lysyl oxidase expression in lung fibroblasts by transforming growth factor-beta 1 and prostaglandin E2. Am J Respir Cell Mol Biol 1994;11:751-755.

-40 Gacheru SN, Thomas KM, Murray SA, Csiszar K, Smith-Mungo LI, Kagan HM: Transcriptional and post-transcriptional control of lysyl oxidase expression in vascular smooth muscle cells: effects of TGF-beta 1 and serum deprivation. J Cell Biochem 1997;65:395-407.

41 Zhang K, Rekhter MD, Gordon D, Phan SH: Myofibroblasts and their role in lung collagen gene expression during pulmonary fibrosis. A combined immunohistochemical and in situ hybridization study. Am J Pathol 1994;145:114-125. 